\title{
EFFECT OF CORTISONE ON THE COURSE OF
}

\section{EXPERIMENTAL SYPHILIS IN THE GUINEA-PIG}

\section{ACTION OF CORTISONE WHEN ADMINISTERED IN VARIOUS DOSES AT VARIOUS TIMES TO GUINEA-PIGS PREVIOUSLY INFECTED INTRADERMALLY WITH T. PALLIDUM*}

\author{
BY \\ KONRAD WICHER AND ADAM JAKUBOWSKI \\ Department of Dermatology and Venereology, University School of Medicine, Bialystok, Poland
}

In the first part of this study on the effect of cortisone on the course of experimental syphilis in the guinea-pig, it was shown that the only suitable method of investigation is that of infection by intradermal injections in the scrotal region. It was also demonstrated that administration of cortisone before infection causes a prolongation of the incubation period, shortens the period during which lesions are evident, and changes their character.

In this second communication it is proposed to investigate the action of cortisone injected at various times after the moment of infection, in order to discover whether different schedules affect the course of the disease.

Turner and Hollander (1950) found that cortisone had a significant effect on the development of syphilitic changes in rabbits; when rabbits were infected intracutaneously on the back with $T$. pallidum, cortisone injected when the changes were most marked caused a certain hypertrophy of the lesions, which became round and convex, with spongy sharply-defined bases, and were filled with a mucoid gelatinous substance, which proved to be hyaluronic acid. This hypertrophy was named the "rebound". The numbers of $T$. pallida in the lesions of the animals to which cortisone had been administered were several times higher than those in the lesions of the control animals.

According to Turner and Hollander (1954), the lesions began to appear at the same time in rabbits to which cortisone was administered before infection and continued during the period of incubation as in the control rabbits, but they developed more slowly. Cortisone administered just before the lesions were due to appear delayed their development, and the

\footnotetext{
* Received for publication September 4, 1963.
}

lesions were, in a certain phase, smaller than in the controls. However, when cortisone was discontinued, the typical "rebound" hypertrophy ensued.

Administration of cortisone when the lesions had begun to disappear caused a reactivation of the lesions and of the "rebound", but when it was given during the period of recovery (when the skin lesions had disappeared) it did not cause any reactivation.

\section{Material and Methods}

Sixty male guinea-pigs were used. They were divided into five groups of twelve according to the time of administration and the dosage of cortisone.

In each group eight animals received cortisone and four served as controls. The same preparation of 11-dihydro17-hydrocorticosterone (from the firm of Continental Pharma, Belgium) was used for this experiment as in the earlier studies.

Group 1.-Cortisone administration was begun on the 7th day before infection. Each guinea-pig received a daily intramuscular injection of $7.5 \mathrm{mg}$./ kg. in suspension (a total of $120 \mathrm{mg}$. in 48 injections).

Group 2.-Cortisone administration was begun on the 7 th day before infection. Each guinea-pig received a daily intramuscular injection of $37.5 \mathrm{mg} / \mathrm{kg}$. in suspension (a total of $337.5 \mathrm{mg}$. in 27 injections).

Group 3.-Cortisone administration was begun on the first day after the lesions had appeared. Each guinea-pig was given a daily intramuscular injection of $7 \cdot 5 \mathrm{mg} . / \mathrm{kg}$. in suspension (a total of $70 \mathrm{mg}$. in 28 injections).

Group 4.-Cortisone administration was begun on the first day after the most intensive lesions had developed. Each guinea-pig was given a daily intramuscular injection of $7.5 \mathrm{mg}$. $/ \mathrm{kg}$. in suspension (a total of $45 \mathrm{mg}$. in 17 injections).

Group 5.-Cortisone administration was begun on the 7 th day after the lesions had begun to disappear. Each guinea-pig received a daily intramuscular injection of $7.5 \mathrm{mg} . / \mathrm{kg}$. in suspension (a total of $45 \mathrm{mg}$. in 17 injections). 
The weights of these guinea-pigs varied between 350 and $420 \mathrm{~g}$. All were injected intradermally into the scrotal fold with a suspension of $T$. pallidum (Nichols strain) having a concentration of $2 \times 10^{6} / \mathrm{ml}$. Groups 1 and 2 were infected at the same time with the same suspension of $T$. pallidum, and Groups 3, 4, and 5 were also infected simultaneously with another suspension of $T$. pallidum in the same concentration as above.

After infection the guinea-pigs were closely observed every day, particular attention being paid to the length of the incubation period, and the duration, character, and sizes of the lesions. Since it had been found in the first part of these experiments that serological and histological examinations did not give useful results, these were not carried out in the present series.

\section{Results}

The results are shown in the Table.

\section{Groups 1 and 2}

Only five of the eight guinea-pigs in each group had skin lesions at the site of injection of $T$. pallidum, but all the control animals in these groups were affected.

Incubation Period.-In Group 1, this varied between 16 and 23 days (mean 18.8) in the treated animals and between 10 and 13 days (mean 11) in the controls. In Group 2, the incubation period was shorter: range 10 to 15 days (mean $12 \cdot 2$ ) in the treated animals and 9 to 12 days (mean 10.1) in the controls.

Duration of Lesions (from first appearance to final disappearance).-This was much shorter in the treated guinea-pigs of Group 1 than in the controls$7 \cdot 2$ compared with $20 \cdot 2$ days. In Group 2 the duration was approximately the same.

TABLE

COMPARISON BETWEEN CORTISONE-TREATED GUINEA-PIGS AND CONTROLS

\begin{tabular}{|c|c|c|c|c|c|c|c|c|c|c|c|}
\hline & \multirow[b]{2}{*}{ Group } & \multirow{2}{*}{$\underset{\text { pigs }}{\text { No. of }}$} & \multirow{2}{*}{$\begin{array}{l}\text { No. of } \\
\text { Sympto- } \\
\text { matic } \\
\text { Infec- } \\
\text { tions }\end{array}$} & \multicolumn{4}{|c|}{ Cortisone } & \multicolumn{2}{|c|}{ Time (days) } & \multirow{2}{*}{$\begin{array}{c}\text { Size of } \\
\text { Lesion } \\
\text { mm. } \\
\text { diameter }\end{array}$} & \multirow[b]{2}{*}{ Character of Lesions } \\
\hline & & & & Started & $\begin{array}{l}\text { Dose } \\
\text { (mg./kg. } \\
\text { day) }\end{array}$ & $\begin{array}{l}\text { No. of } \\
\text { Injec- } \\
\text { tions }\end{array}$ & $\begin{array}{l}\text { Total } \\
\text { Dose } \\
\text { (mg.) }\end{array}$ & $\begin{array}{l}\text { Incu- } \\
\text { bation }\end{array}$ & $\begin{array}{c}\text { Duration } \\
\text { of } \\
\text { Lesions }\end{array}$ & & \\
\hline \multirow[t]{2}{*}{ I } & Cortisone & 8 & 5 & $\begin{array}{l}7 \text { days } \\
\text { before } \\
\text { Infection }\end{array}$ & $7 \cdot 5$ & 48 & 120 & $\begin{array}{r}16-23 \\
(\text { mean } \\
18 \cdot 8)\end{array}$ & $\underset{7 \cdot 2)}{5-10}$ & $2-5$ & $\begin{array}{l}\text { Hypertrophic, slightly in- } \\
\text { filtrated, pale, slightly } \\
\text { convex nodules. }\end{array}$ \\
\hline & Control & 4 & 4 & - & - & - & - & $\begin{array}{c}10-13 \\
(\text { mean } \\
11)\end{array}$ & $\begin{array}{l}14-26 \\
(\text { mean } \\
20 \cdot 2)\end{array}$ & 7- 9 & $\begin{array}{l}\text { Hypertrophic, strongly in- } \\
\text { filtrated, reddened, rub- } \\
\text { bery nodules with distinct } \\
\text { margins and central ul- } \\
\text { cerations. }\end{array}$ \\
\hline \multirow[t]{2}{*}{ II } & Cortisone & 8 & 5 & $\begin{array}{l}7 \text { days } \\
\text { before } \\
\text { Infection }\end{array}$ & $37 \cdot 5$ & 27 & $37 \cdot 5$ & $\begin{array}{l}10-15 \\
(\text { mean } \\
12 \cdot 2)\end{array}$ & $\underset{8)}{\substack{6-11 \\
8)^{2}}}$ & $2-4$ & $\begin{array}{l}\text { Hypertrophied, slightly } \\
\text { infiltrated, pale, slightly } \\
\text { convex nodules. }\end{array}$ \\
\hline & Control & 4 & 4 & - & - & - & - & $\begin{array}{c}9-12 \\
(\text { mean } \\
10 \cdot 1)\end{array}$ & $\begin{array}{c}12-24 \\
(\text { mean } \\
19)\end{array}$ & $8-14$ & $\begin{array}{l}\text { Hypertrophied, strongly } \\
\text { infiltrated, reddened, rub- } \\
\text { bery nodules with distinct } \\
\text { margins and central ul- } \\
\text { cerations. }\end{array}$ \\
\hline \multirow[t]{2}{*}{ III } & Cortisone & 8 & 8 & $\begin{array}{l}\text { 1st day } \\
\text { after Incu- } \\
\text { bation }\end{array}$ & $7 \cdot 5$ & 28 & 70 & $\begin{array}{c}12-15 \\
(\text { mean } \\
13)\end{array}$ & $\begin{array}{l}12-19 \\
(\text { mean } \\
15 \cdot 5)\end{array}$ & $7-13$ & \multirow{2}{*}{ As above } \\
\hline & Control & 4 & 3 & - & 一 & - & - & $\begin{array}{c}10-12 \\
(\text { mean } \\
10 \cdot 7)\end{array}$ & $\begin{array}{c}11-16 \\
(\text { mean } \\
14)\end{array}$ & $7-10$ & \\
\hline \multirow[t]{2}{*}{ IV } & Cortisone & 8 & 7 & $\begin{array}{c}\text { 1st day } \\
\text { after } \\
\text { Observing } \\
\text { most } \\
\text { Intensive } \\
\text { Lesions }\end{array}$ & $7 \cdot 5$ & 17 & 45 & $\begin{array}{c}12-16 \\
(\text { mean } \\
14 \cdot 3)\end{array}$ & $\begin{array}{l}11-14 \\
(\text { mean } \\
12 \cdot 8)\end{array}$ & \multirow[t]{2}{*}{$7-10$} & \multirow[t]{2}{*}{ As above } \\
\hline & Control & 4 & 3 & - & - & - & - & $\begin{array}{r}10-13 \\
(\text { mean } \\
11 \cdot 5)\end{array}$ & $\begin{array}{c}11-17 \\
(\text { mean } \\
14 \cdot 2)\end{array}$ & & \\
\hline \multirow[t]{2}{*}{$\mathbf{v}$} & Cortisone & 8 & 8 & $\begin{array}{c}\text { 7th day } \\
\text { after } \\
\text { Symptoms } \\
\text { began to } \\
\text { disappear }\end{array}$ & $7 \cdot 5$ & 17 & 45 & $\begin{array}{r}10-12 \\
(\text { mean } \\
11 \cdot 1)\end{array}$ & $\begin{array}{r}11-15 \\
\left(\begin{array}{c}\text { mean } \\
13 \cdot 2)\end{array}\right.\end{array}$ & \multirow{2}{*}{$7-10$} & \multirow{2}{*}{$\begin{array}{l}\text { As above, but central } \\
\text { ulcerations not noted. }\end{array}$} \\
\hline & Control & 4 & 3 & - & - & - & 一 & $\begin{array}{c}10-12 \\
\text { (mean } \\
11)\end{array}$ & $\begin{array}{l}11-16 \\
(\text { mean } \\
13 \cdot 5)\end{array}$ & & \\
\hline
\end{tabular}


Nature of the Lesions.-In guinea-pigs treated with cortisone, hypertrophied, slightly infiltrated, pale, somewhat convex, demarcated nodules of diameter 2 to $5 \mathrm{~mm}$. (Fig. 1) appeared at the site of the $T$. pallidum injection. The lesions rarely became ulcerated, and resolved spontaneously in a short time. In the controls, on the other hand, an intense reddening was followed by the appearance of infiltrated nodules with clearly marked edges, typical of the syphilitic nodule, with a rubbery consistency (Fig. 2). In the controls the lesions were slightly larger and were seen to disintegrate in the middle with deep ulcerations as the nodule grew; the lesions took much longer to heal and left superficial scars. In both treated and control animals infiltration of the testicles and a swelling of the inguinal glands were noted. No T. pallida were found in puncture fluid from the testicles and inguinal glands by dark-field examinations carried out on several occasions.

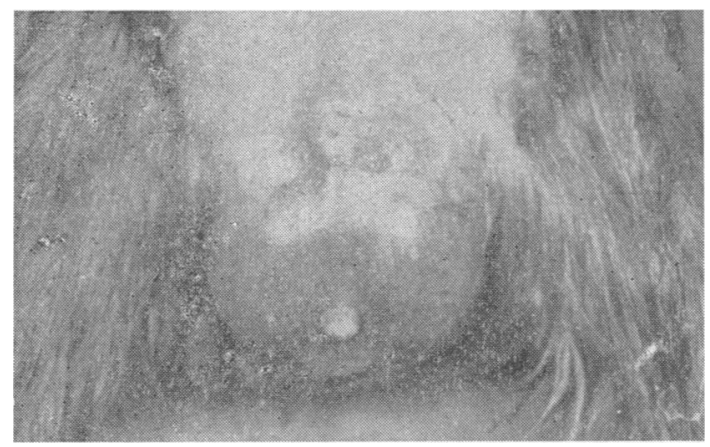

FIG. 1.-Guinea-pig No. 288, from experimental Group 1, 17 days after intradermal inoculation, showing maximal clinical lesions.

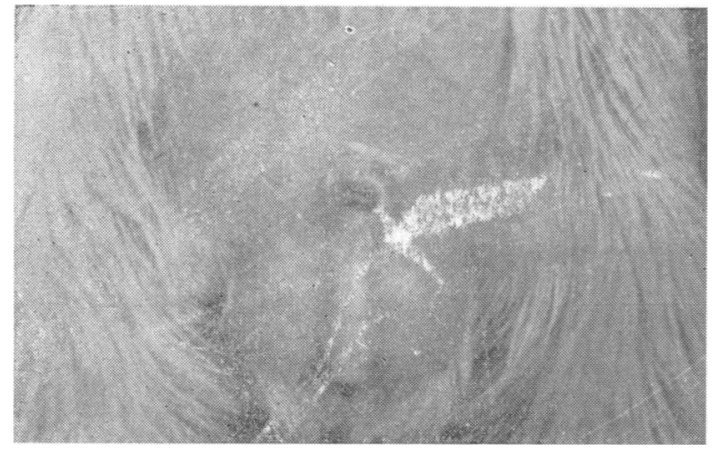

FIG. 2.-Guinea-pig No. 292, from Control Group 2, 25 days after intradermal inoculation, showing lesions beginning to subside.

\section{Groups 3, 4, and 5}

No significant differences were observed between the guinc:-pigs treated with cortisone and the control animals. Only in Group 3, in some of the guinea- pigs to which the first cortisone injection had been given on the first day after incubation, were the skin lesions somewhat larger. Figs 3 and 4 illustrate the typical lesions occurring in Groups 3 and 4.

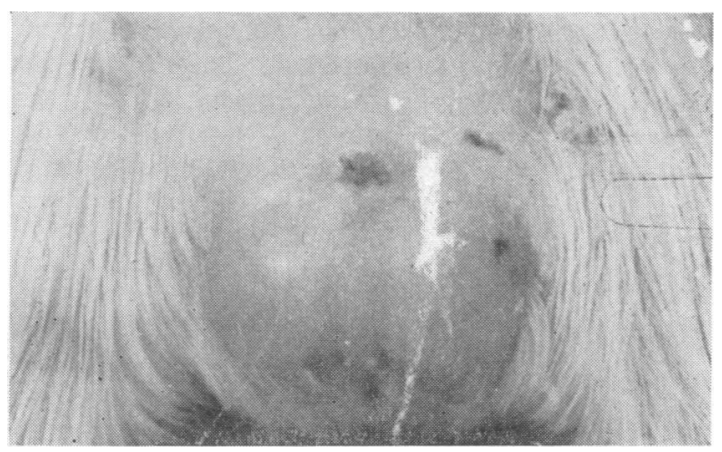

FIG. 3.-Guinea-pig No. 296, from Control Group 3, 17 days after intradermal inoculation, showing maximum clinical lesions.

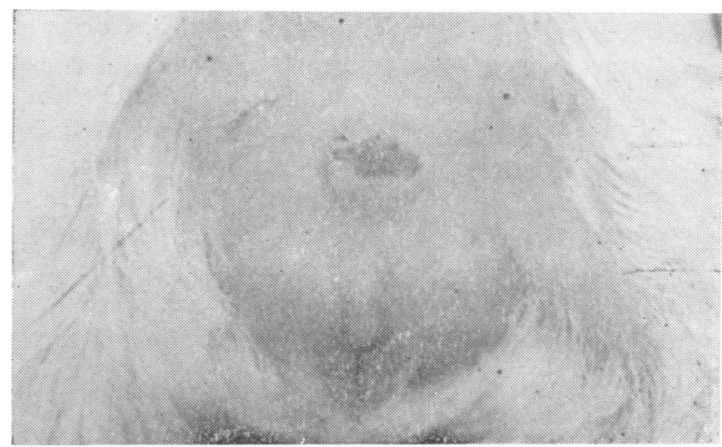

FIG. 4.-Guinea-pig No. 299, from Experimental Group 3, 17 days after intradermal inoculation, showing maximum clinical lesions.

The numbers of $T$. pallida in all groups were counted on a dark-field at various stages of development of the lesions. No differences were noted between the guinea-pigs treated with cortisone and the controls, the numbers of organisms varying between one and three per field. No T. pallida at all were found in certain lesions of all groups, particularly when, although still visible, they had begun to disappear.

\section{Blood Tests}

The blood was examined in all five groups before cortisone was administered, after the first seven injections, and every week thereafter up to the 14th day after the last cortisone injection. These examinations were carried out on four guinea-pigs chosen at random from each experimental group and on two chosen at random from each control group. Though various doses of cortisone had been administered, no distinct differences from the control animals were observed, but there were significant individual 
variations in the numbers of leucocytes and lymphocytes. The total number of lymphocytes in the controls varied from 32 to 84 per cent. and in the cortisone-treated animals from 40 to 92 per cent. The number of leucocytes in the controls varied from 6,000 to 14,000 , and in the cortisone-treated animals from 5,400 to 16,800 . Before the first injection of cortisone, the leucocytes varied from 8,200 to 14,000 and the number of lymphocytes from 45 to 84 per cent. These wide individual differences made it impossible to trace any pattern of change in the blood of the guinea-pigs examined.

\section{Discussion}

When our results are compared with those of Turner and Hollander $(1950,1954)$ with rabbits, certain differences are observed in the mechanism of cortisone action on guinea-pigs infected with $T$. pallidum. Cortisone administered to rabbits before infection and throughout incubation does not affect the period of incubation and causes only a somewhat slower development of the lesions. In guinea-pigs to which cortisone was administered on the 7th day after infection and throughout incubation, the lesions appeared much later than in the controls.

After the administration of cortisone before infection with $T$. pallidum, lesions were observed in fewer animals and cortisone may therefore be said to have inhibited the normal development of skin lesions.

The dosage seems to affect the length of incubation. In guinea-pigs injected with $37.5 \mathrm{mg}$. $/ \mathrm{kg}$. daily the incubation lasted 10 to 15 days, whereas in those injected with $7.5 \mathrm{mg} . / \mathrm{kg}$. daily it lasted 16 to 23 days. Perhaps in those which received large doses $(37.5 \mathrm{mg} . / \mathrm{kg}$.), its excretion was accelerated. The treated guinea-pigs reacted to $T$. pallidum infection similarly to the control animals. 'The size of the dose had no effect on the duration of the lesions.

The administration of cortiscne to rabbits just before the lesions would hav ' appeared delayed their development, and when cor:isone was discontinued the typical "rebound" lesions occurred. But we observed no difference in Group 3 between the controls and the treated guinea-pigs, except that the lesions were a little more extensive in the latter. (The difference was too slight to be interpreted as having any connexion with the action of cortisone.)

The guinea-pigs of Group 4 (in which cortisone treatment was commenced on the first day after lesions were most evident) differ from Turner and Hollander's rabbits. In the rabbits hypertrophic lesions leading to the so-called "rebound" were filled with hyaluronic acid with large numbers of $T$. pallida: in the guinea-pigs there was no hypertrophy, no difference in the consistency of the ulcerations, and no increase in the numbers of T. pallida.

When administered to rabbits while the lesions were beginning to disappear, cortisone caused a reactivation of the lesions, but no such process was observed in the guinea-pigs of Group 5.

The studies of blood morphology disclosed no substantial changes, the large individual variations making it impossible to demonstrate any typical differences between the groups of animals. According to Schermer (1954), however, such variations are typical of the guinea-pig. He gives the number of leucocytes in healthy guinea-pigs as 3,200 to 15,000 and of lymphocytes as 55 to 80 per cent.

In this series of experiments, not one guinea-pig died, although cortisone was administered in large doses for several weeks. After the experiments the treated guinea-pigs behaved normally and no deaths occurred. This may be due to rapid excretion of cortisone from the guinea-pig's body. Turner and Hollander reported that several syphilitic rabbits treated with cortisone died, usually as a result of their defencelessness against organisms other' than T. pallidum.

The mechanism of cortisone action in experimental syphilis in rabbits has also been investigated by Gastinel, Collart, Vaisman, Hamelin, and Dunoyer (1960) and Schmidt, Dorph-Petersen, and Bentzon (1957). On the whole, their experiments have shown that cortisone injected into rabbits infected with $T$. pallidum causes extensive syphilitic changes, depending on the time, dosage, and method of administration.

\section{Conclusions}

From the experiments presented here it is possible to draw the following conclusions:

(1) Administration of cortisone before infection changes the course of experimental syphilis in the guinea-pig (Groups 1 and 2), but has no such effect when administered after incubation of the infection (Groups 3 to 5).

(2) The course of $T$. pallidum infection in these guinea-pigs differs from that in rabbits similarly treated.

(3) The mechanism of cortisone action in the infected guinea-pigs appears to differ from that in rabbits similarly infected.

(4) In the rabbit treated with cortisone, the $T$. pallidum may be separated from its host, as Turner and Hollander suggested, whereas this separation does not occur in the guinea-pig. 
(5) Our results may be due to a too weak action of cortisone or to a too rapid excretion of cortisone from the guinea-pig. As the ability of the guinea-pig to excrete cortisone has not yet been investigated this point is subject to further investigation.

\section{Summary}

The effect was investigated of cortisone on the course of experimental syphilis in 60 guinea-pigs infected intradermally with $T$. pallidum. Cortisone administration was begun at various times before or after infection and was given in various doses.

Administration of cortisone before intradermal infection prolonged the incubation period, shortened the duration of skin lesions, and affected their intensity, but large doses of cortisone before infection did not have this last effect.

Cortisone injected on the first day after the period of incubation, when the lesions were at their worst, and when the lesions were beginning to disappear, had no effect on the nature of the symptomatic infection. The mechanism of the action of cortisone on experimental syphilis in the guinea-pig differs from that in the rabbit. Reasons for this difference are discussed.

\section{REFERENCES}

Gastinel, P., Collart, P., Vaisman, A., Hamelin, A., and Dunoyer, F. (1960). Ann. Derm. Syph. (Paris), 87, 612.

Schermer, S. (1954). "Die Blutmorphologie der Laboratoriumstiere". Barth, Leipzig.

Schmidt, H., Dorph-Petersen, L., and Bentzon, M. W. (1957). Brit. J. vener. Dis., 33, 259.

Turner, T. B., and Hollander, D. H. (1950). Bull. Johns Hopk. Hosp., 87, 505.

—, - (1954). Amer.J. Syph., 38, 371.

Effet de la cortisone sur la syphilis expérimentale chez le cochon d'Inde. II.

RÉSUMÉ

On étudia l'effet de la cortisone sur la syphilis expérimentale chez 60 cochons d'Inde infectés de $T$. pallidum par la voie cutanée.

Différentes doses de cortisone furent administrées en temps variés avant ou après l'infection. La cortisone administrée avant l'infection par la voie cutanée prolongea l'incubation, abrégea la durée des lésions cutanées, et modifia l'intensité des lésions; néanmoins les doses très grandes n'eurent pas ce dernier effet.

La cortisone administrée le premier jour après l'incubation, quand les lésions étaient les plus sévères, et lorsqu'elles commençaient à guérir, n'eut aucun effet.

Le mode d'action de la cortisone n'est pas le même chez le cochon d'Inde que chez le lapin. On discute les causes de cette différence. 